\title{
Aesthetic visions of mural painting in international airports (A Proposal of experience for the researcher at a Yemeni airports)
}

\author{
${ }^{1}$ Nermen Elmasry, ${ }^{2}$ Zeinab Mohamed Nour, ${ }^{3}$ Hayat Mohammed Maqbool \\ ${ }^{1}$ BDS, MSc, Phd \\ Professor of Painting department, Faculty of Fine Arts - Helwan University Cairo, Egypt \\ ${ }^{2}$ BDS, MSc, Phd \\ Professor of Painting department, Faculty of Fine Arts - Helwan University Cairo, Egypt \\ ${ }^{3} \mathrm{BDS}, \mathrm{MSc}$ \\ External Residence of Painting department, Faculty of Fine Arts - Helwan University Cairo, Egypt
}

\begin{abstract}
:
Purpose: This work is a trial study for International Airports esthetics developments. The work was introducing explore the disparity and activities of that airports as well as its benefit to tourism growth internationally for a clear understanding and appreciation of the importance of mural and artistic works in the architecture of international airports.

Materials and methods: The practical experience of the researcher is based on three main axes, through which it deals with some aspects of the Yemeni environment to be applied within some of the wall works in Yemen airports. All murals are decorated with glass mosaic materials and ceramics on large wooden panels. The $1^{\text {st }}$ axis: murals inspired by the ancient heritage of Yemeni architecture. The $2^{\text {nd }}$ axis: Murals inspired by the picturesque Yemeni nature. The $3^{\text {rd }}$ axis: murals inspired by the social and psychological state of the Yemeni human being.

Conclusion: Many Yemeni institutions' buildings are decorated with murals, paintings, and other subjects related to that region or community. We note that the government of Yemen has taken care of this type of architecture, such as the art of murals.

Recommendations: The mural art works are not suitable for placing in international airport halls except with basic points that are supposed to be taken into account in the mural work to be placed inside airports, where it is recommended to take into account the three main axes: the environment, the design, and the materials in which these murals were completed.
\end{abstract}

Keywords: mural, airports, Yemeni airports, esthetics.

\section{Introduction}

The mural is considered one of the most important plastic artists whose responsibility is to convey the artist's message and his creative expression of society, tourism and intellectual who is familiar with the culture of his society and can present it creatively to the other in modern and contemporary level.

Because the contemporary building has kept pace with modern scientific development, a modern and contemporary architecture has emerged and a broad formative development has been followed by an increase in population mobility and a rapid development in transportation. ${ }^{(1)}$

The fact that art ,generally, and the mural are specifically linked to an organic association with architecture has allowed the mural photographer to be in divinable part of another team, namely the architect, sculptor, decorator and others with other disciplines associated with architecture in a unit aimed at reaching a successful building with a specific aesthetic and functional message.

As the architecture of international airports and its various lounges is one of the most important public stations where different social groups meet with different culturally and socially behavior, this type of 
architecture has a special characteristic that distinguishes the culture and level of sophistication and progress of the society in which this airport is for any country.

Hence the importance of mural works in the buildings to highlight them aesthetically and culturally as well as to highlight the civilization and culture of the surrounding society where it gives a beautiful impression to travelers or arrivals about the culture of that country and society. ${ }^{(2)}$

Because the place and its important focal point in the mural arts, the airport lounges and the importance they pose for travelers and arrivals during the transit and waiting for flights were among the most suitable architectural places for mural works where they allow a large number of the audience to enjoy the contents of these works.

Hence the importance of this study to enrich the aesthetic side of the mural works in the Yemeni airport lounges.

\section{Method and steps:}

Follows historical analytical methods, the research where a sophisticated approach was used, that includes historical methods and art criticism for many Yemeni and international murals Airports.

\section{Associated Studies}

With regard to studies and studies, the appeal and the mural in the smuggling abroad and the role of the mural in the aesthetics of architecture for the international airport, the researcher did not find enough aforementioned special studies and designs. Where I listed what was collected and revised from references and international publishing houses.

\section{Chapter one}

The study in this chapter dealt with a historical introduction to the development of the construction of some international airports and their own architecture, where it addressed the beginning of the emergence of airports and the importance they reflect in light of the contemporary global challenges.

Airports began as a grassy area for aircraft take-off and landing sites, and there are hangars for replacement, storage and control sites, and that was approximately in 1909 AD. France and Norway were among the first to provide these concessions at airports at that time. ${ }^{(3)}$

In the suburb of Le Bourget near Paris in France, the first airport for commercial air navigation was established in one direction from the military air zone, and after 5 years, the Bourget airport was officially opened in 1919 AD, it was initially a subsidiary airport and then considered a major commercial air station, in 1981, the activities of this airport were focused primarily on commercial and business aviation and is now the first airport in Europe for businessmen. The primitive shape of this airport or station as a model for the shape of most airports that appeared in that period, which were trying to give in their shape the features of the train stations in order to give the impression to the traveler that there is no difference in traveling in the air, so it was similar to the train station such as Le Bourget Airport in France, which was established in 1927 $\mathrm{AD}$ (Figure 1 ) and its hangars and car workshops, and the interior design of airports resembles a car park fence $^{(4)}$ 


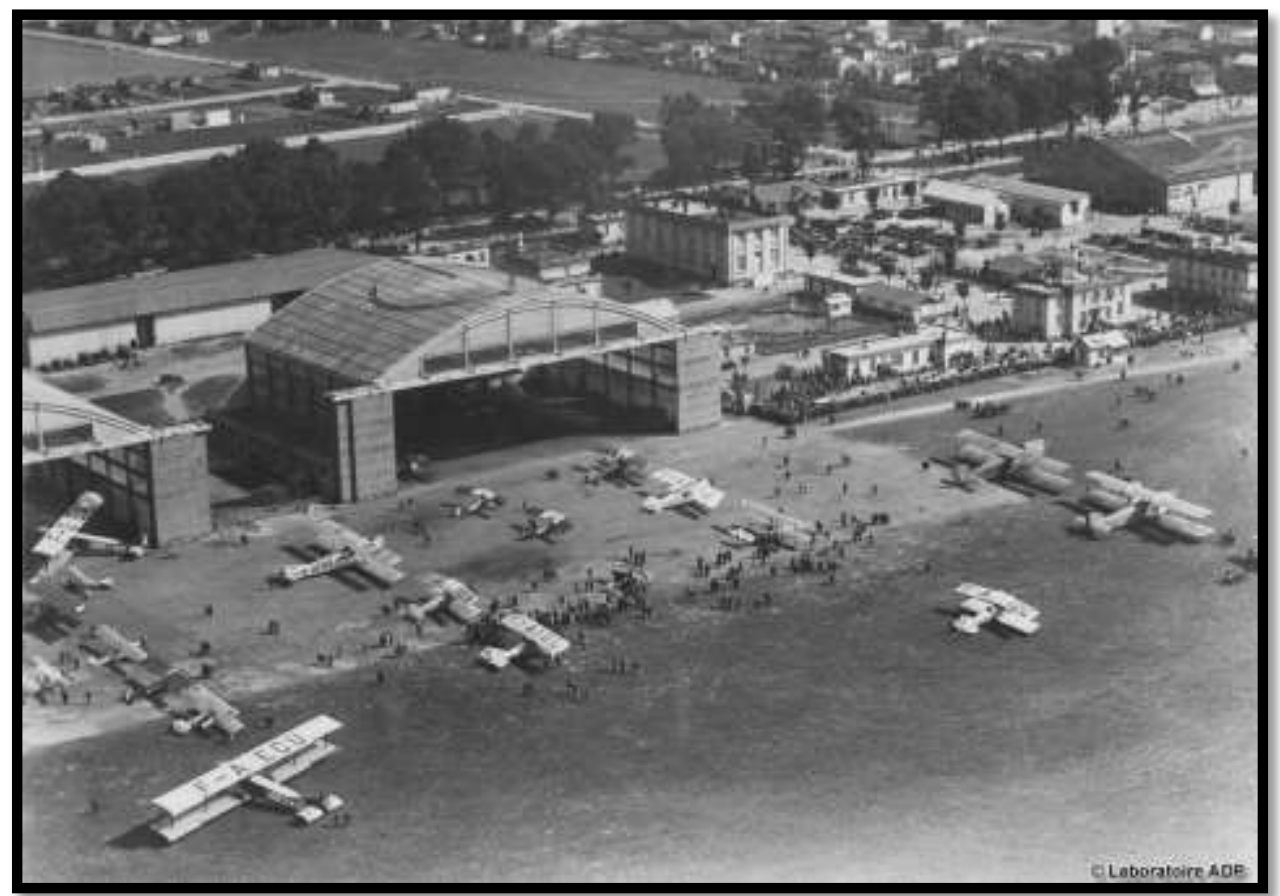

Figure (1). Beginning of the Le Bourget France airport in 1927 AD

The increase in the movement of mail and goods transport led to the necessity of amending the internal systems of passenger buildings to suit this number of passengers and goods. This period was characterized by the existence of corridors between the passenger building and aircraft parking spaces and berths between ground transportation and the airport, these changes led to the emergence of the star shape or the so-called "finger system" in the 1950's in the United States and immediately after that appeared in Europe, and this system is summarized in that the passengers gather in the central area of the lanes and then move out of the corridor in the form of a star or fingers to Departure halls, as shown by (Figure 2) a picture for Charles de Gaulle international Airport at Paris. ${ }^{(5)}$

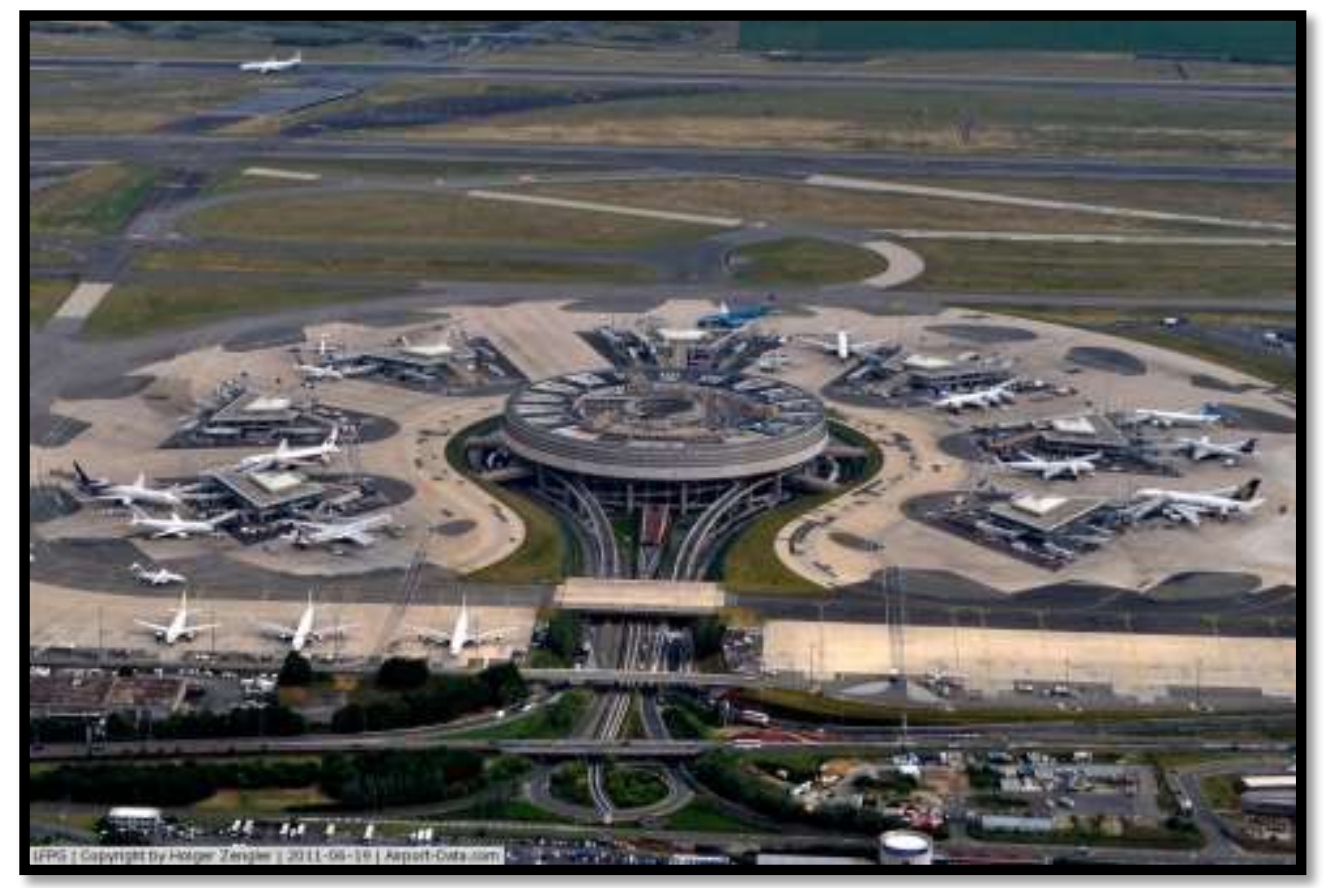

Figure (2): Charles de Gaulle International Airport CDG in France.

\section{Chapter two}


Chapter 2 was studded heritage as an important source of inspiration in the mural works at some international airports and the methods of their formulation and the aesthetic values that have surrounded the heritage and rituals of their peoples.

The mixture of heritage and environment is a fertile source and a source of artistic creativity, especially for mural artists, because the contemporary mural artist bears an artistic and cultural responsibility towards society through his enlightening message and visual culture for the receiving audience, the artist's ingenuity and creativity appears through the selection of special ways to present this heritage, including its myths, symbols, and suggestions; The heritage "must be presented in a holistic form by presenting it as elements or as processes connected to each other and not as separate parts. ${ }^{(6)}$

In an annual celebration of one of China's minority groups, an artist is depicted in the form of a mural of naked people. Such scenes of nudists

were unfamiliar in Chinese society at that time, that mural (Poem to Life or "Water Splashing Festival"), and its nude female figures, caused a fierce debate about nudity in art, and this work came at a time when the country was undergoing an incomplete dismantling of the Maoist system and its ideologies, communist symbols and character worship, the artist addressed the dimensions of this work in one of the articles, Yuan said in a 2008 interview that he painted nude women out of an artistic motive to show the beauty of the human form and test the level of society's tolerance as reform unfolded, "I was drawing a shower scene, so it is natural that people will not have any clothes but to get that, the officials had to agree, I drew extra lines in my chart to make it look like the women were wearing something, and then I erased that extra amount of lines before I finished painting, by the time the authorities found out, it was too late for them. to do anything". Many have seen this painting as influential, reflecting the changing times and attitudes in China. (7)

The work was characterized by lush tropical colors and clear sensual lines, for three naked women washing their long locks. The artist focused on the beauty of the surface using gilded paper under a black background, sometimes influenced by the works of the artist (Gustav Klimt) and this influence had an impact on the creativity and innovation of the Chinese artist Yuan Shuneng in his presentation ${ }^{(8)}$ inside The airport is a bold work that was a new addition to Chinese art despite its rejection and struggle. Figure (3)

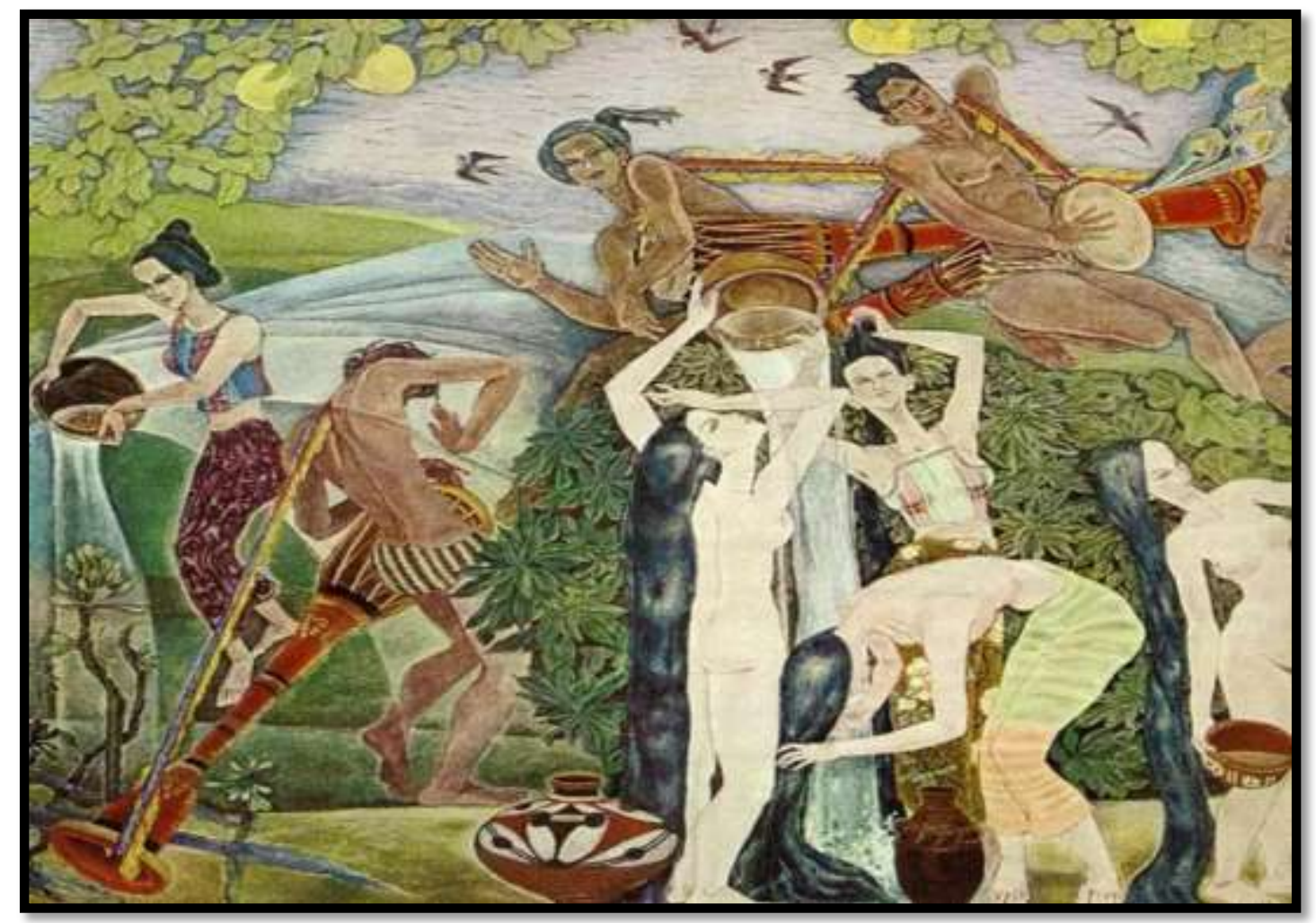

Figure (3): Detail from the mural, Yunnan Provincial Water Festival 1979, Beijing International Airport by Yuan Yunsheng, oil on canvas, 76x58cm, 1979. 
Metaphor different gestures and hand movements of in Indian classical dance represented as a mural in IGI Airport. Fig (4). The mural work is designed and installed on a 240-meter-long wall, bronze and copper by Indian artist and designer Ayush Kasliwal, a heritage used as a inspiration from traditional Indian dance. This mural belongs to Indira Gandhi International Airport of New Delhi. It is inside on the wall of airport. It is 'three dimensional' mural. In this mural different poses of hand situation 'Mudras' are depicted, all to gather there are nine mudras. They are like Varada mudra, Abhaya mudra, Gyan mudra, Surya mudra, Yoga mudra etc. These hand situations are made with fiber and placed with equal distance. Rest of the area is covered with convex mirrors. It is about fifty-meter long. Hand situation are in grayish-blue color and convex mirrors are in golden color. ${ }^{(2)}$

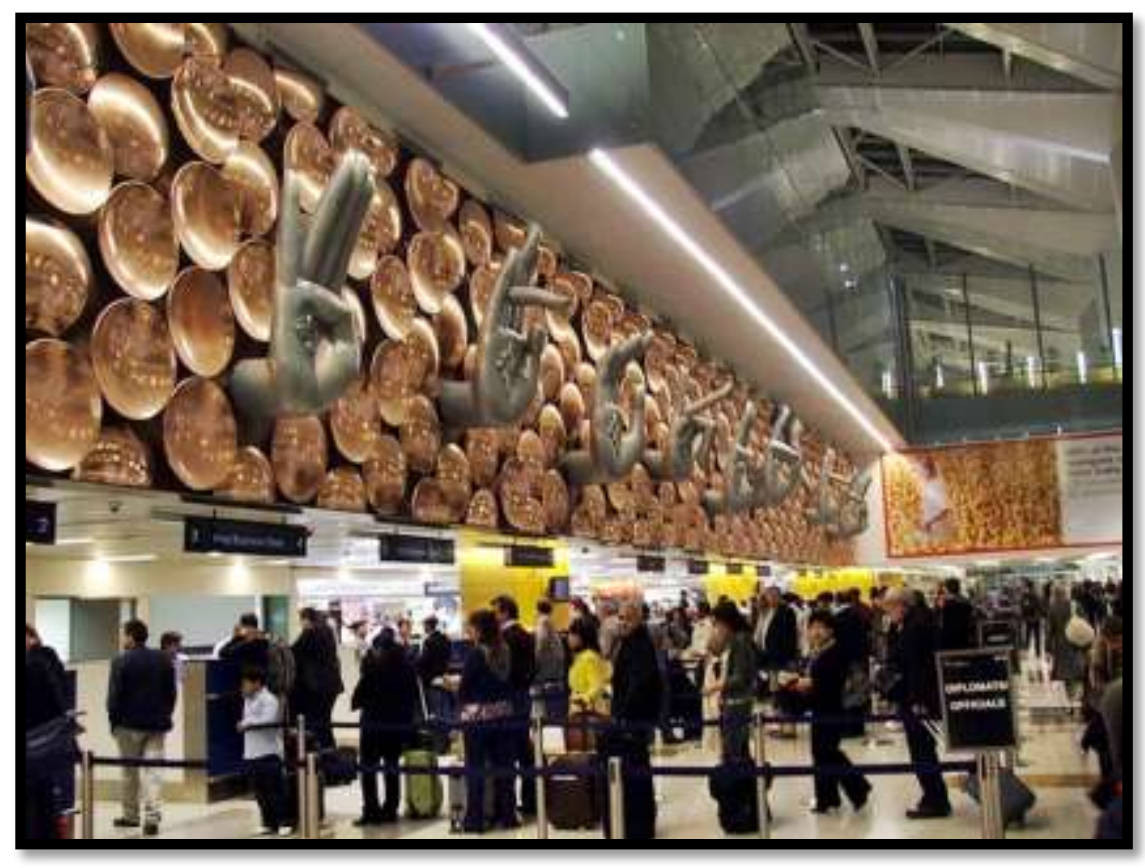

Figure (4). Indira Gandhi International Airport of New Delhi.

The Egyptian artist's artistic production was characterized by his strong association with Egyptian privacy and emphasized the role of the environment effectively in shaping the art of Egyptian heritage across different civilizations and in highlighting the artistic components of this heritage" which shows the automatic and strong interaction between the artist and the components of the different environment in which he lives throughout the ages and Egypt's excellence and uniqueness in the multiplicity of civilizations and cultures over thousands of years the main role that made the Egyptian artist loaded with a long heritage diversity between ancient Egyptian heritage and Coptic heritage and Islamic heritage and heritage Lowbrow but The methods of artistic expression differed in these arts and ages in different ways and means of artistic expression in form and subject matter, but all were characterized by environmental features, some direct and others indirect due to intellectual, cultural and ideological motives in each of these times.

This was clearly mentioned in the mural of Aswan International Airport in Egypt, where the walls of the airport are covered with a mural executed by the tiles of the figure (5) of the designers and executor's artist Mohamed Zenham and the artist Ibrahim Badawi. This mural implemented in the façade of the external airport wall, which was completed and installed in 1997 and through direct talk to one of the artists carrying out the work, the artist Ibrahim Badawi he stated that : the processing of tiles did not meet the same design specifications in Egypt, which necessitated the project's organizers and artists to use factories in Germany to implement and manufacture tiles of ceramic in thermal colors and surround the top of the portrait with a wide belt in blue color. ${ }^{(9)}$ 


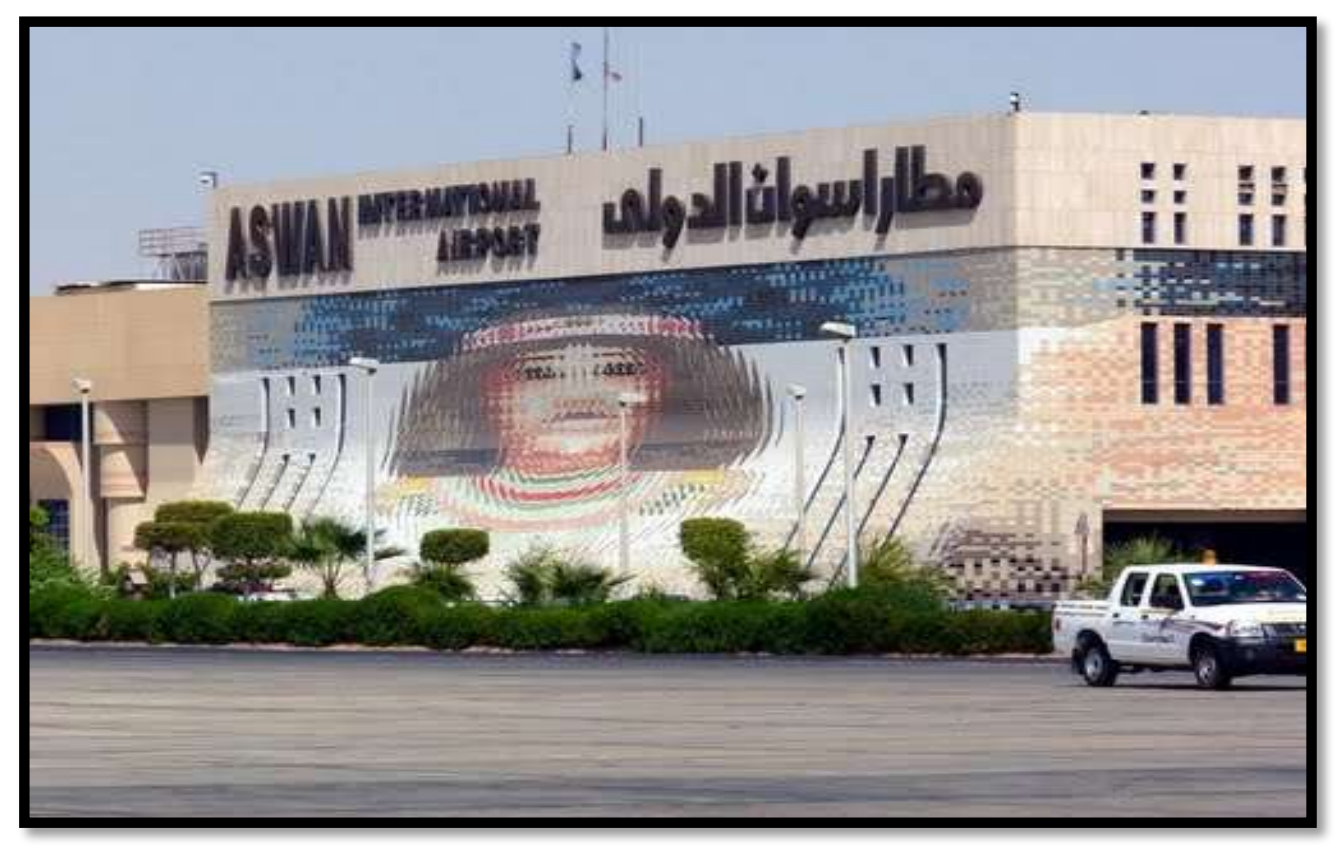

Figure (5). The façade of Aswan International Airport was a ceramic mural by Princess Nefert, executed by mohammed Zinham and Ibrahim Badawi

The design was a portrait of the wife of Prince Ra'a Hattab, her name Nefert, and means beautiful and mimics the original statue of Princess Nefert in the position of sitting with a backrest extending beyond the shoulders and wearing a short wig based on the neck and shoulders and shows the natural hair from the bottom of the wig, which is black in color and wears a wreath decorated with flowers.

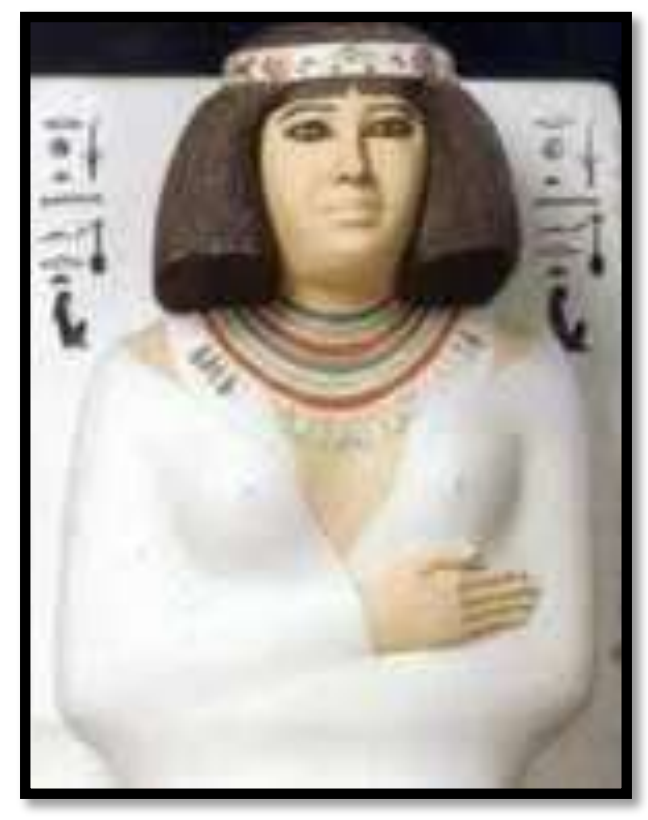

Figure (6) The original statue of Princess Nefert, wife of Prince Ra'a, was inspired by the mural in the façade of Aswan Airport.

\section{Chapter three}

The third chapter deals with the visions of mural photography in international airports, the features of mural photography, the privacy it carries, and the technical programs' experiences at airports, as well as the technical treatments for some of the works found in the halls of some airports. Art in public spaces is an easily accessible form of art created with the intent of being seen by the general public, to introduce art into 
everyday life and aesthetic and visual education, but also as a means to help residents relate to their environment.

Since the early eighties of the last century, art in public spaces has been advocated as a contribution to alleviating a range of environmental, social and economic problems that may arise in society and in the architectural or social environment," says Tim Hall and Chereen Smith since In the 1980s, public art became closely associated with the renewal of cities, the aesthetic enhancement of urban environments, the promotion of tangible improvements in people's lives, and public art becoming increasingly ubiquitous in the economic, social, and cultural renewal of these places. ${ }^{(10)}$

Murals are a form of public art and help to provide a sense of place, especially if local artists and young people are participating in it. Murals reflect the uniqueness of the neighborhoods and cities that surround them and they can give a message about the aesthetics and history of the place and show pride in the cultural values of the community, depending on the size, shape and theme of the mural is one Of the arts that give privacy to the place, as a mural in the city of Bergamo in the arrival hall of Orio airport in Italy, by an artist from the city of Bergamo who is respected by contemporary Italian artists, that artist is Andrea MastroVito.

The mural of Andrea MastroVito consists (Fig. 7) of three hundred panels of cardboard on a solid base showing the viewer the treasures of the city of Bergamo from art, culture, history and sports, artist Andrea Mastro Veneno designed this oil mosaic as a huge frame for hundreds of small paintings linked together in continuity from one to the other forming one mural through Looking at it from afar, historical figures from the past and the present appear, telling the viewer about their stories and the stories of the city at one glance, and in the background are traces of the city. The artist used shadows with each color from gray to light red, and when the final installation of the mural employed a wall 15.50 meters long and 3.50 meters high in the front of one of the airport terminals. ${ }^{(11)}$
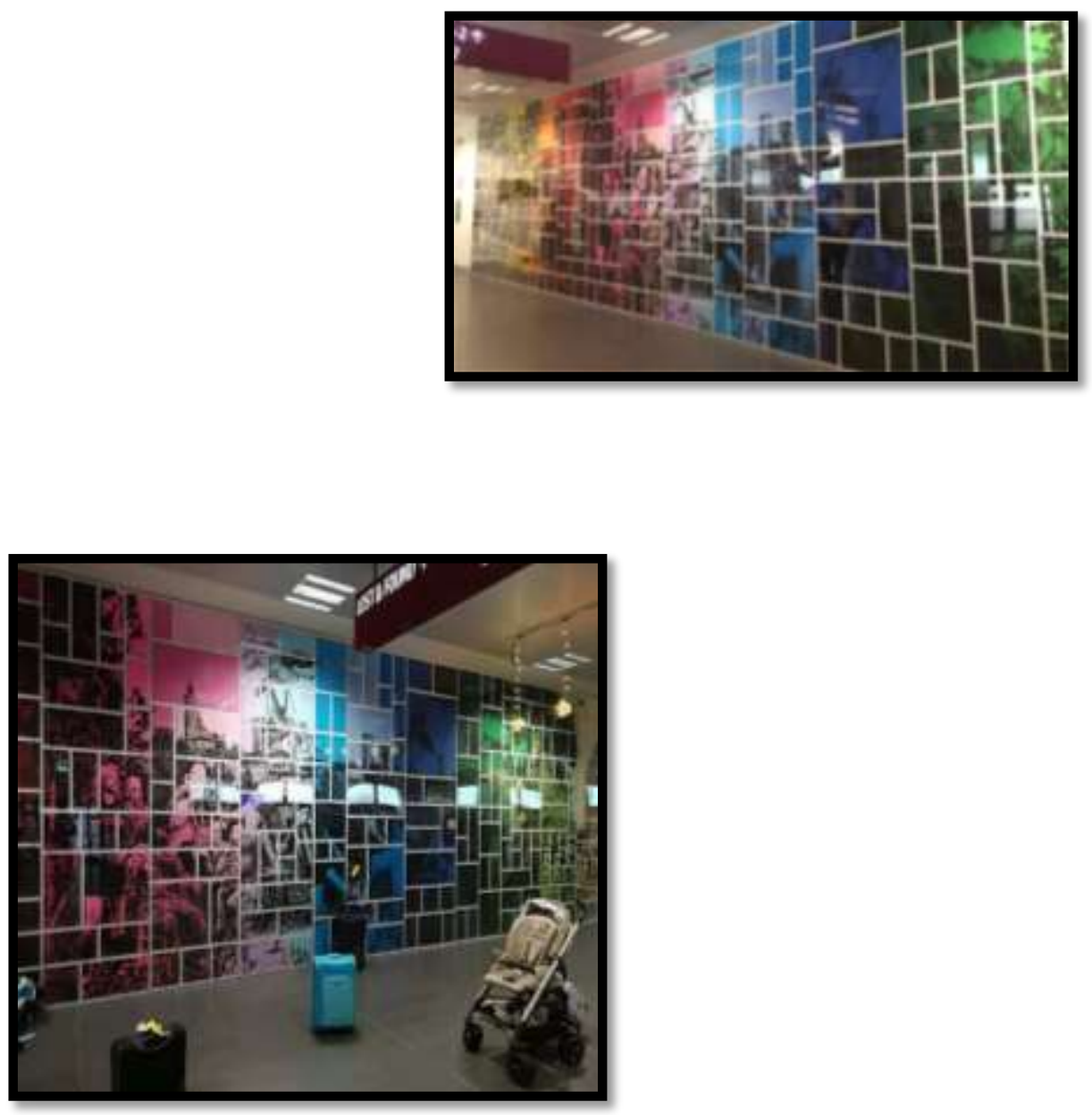

Figure (7) Bergamo mural by Andrew Maestro at Orio International Airport. 
Martin Donlin is an artist who specializes in architectural stained glass murals and has worked across public buildings in the United Kingdom, Ireland Germany and in the United States of America. ${ }^{(12)}$ The murals, which the artist created at Indianapolis International Airport, (Fig. 8) are a collection of screenprinted ceramics and painted acid-lacquered glass with bold imagery for impact but contain intricate small details that can be seen up close. This mural features bold imagery and color paired with intricate detailing. Includes landscapes, a world map, and a summary of the North Carolina road map.

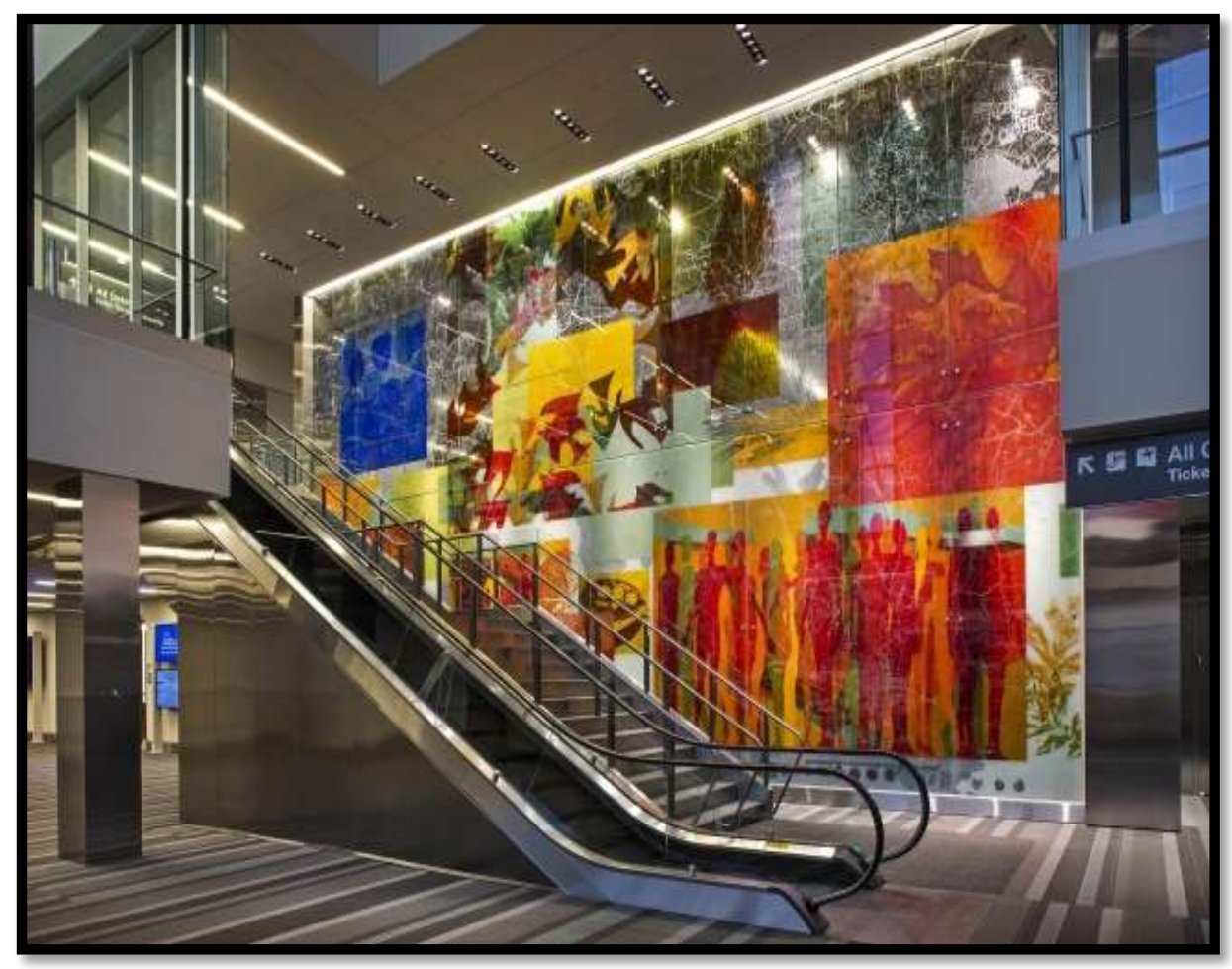

Figure (8) Martin Dolin mural glass works in INDIANAPOLIS airport.

Some windows have acid etched text on the surface of the glass, while others rely on references to the local landscape at different times of the day and year. This collection of murals in this airport is one of the largest stained glass projects in the world which is over 500 square meters and includes 14 windows of different sizes with 114 sealed units and 2385 pieces of handmade glass. ${ }^{(13)}$

\section{Chapter Four}

This chapter was deal with the practical experience of the researcher which was based on three main axes, through which it deals with some aspects of the Yemeni environment to be applied within some of the wall works in Yemen airports. All murals are decorated with glass mosaic materials and ceramics on large wooden panels.

The $1^{\text {st }}$ axis: murals inspired by the ancient heritage of Yemeni architecture.

The $2^{\text {nd }}$ axis: Murals inspired by the picturesque Yemeni nature.

The $3^{\text {rd }}$ axis: murals inspired by the social and psychological state of the Yemeni human being.

\section{The first axis: The Yemeni building}

The Yemeni building is a distinctive model and has its characteristics and basic elements that may not exist in other styles and these elements appear in the distinctive construction of palaces and mosques different Yemeni from one province to another, so the architectural facades in Yemen are one of the greatest sources of inspiration for artists.

Thus, the Yemeni civilization and its distinctive architecture is considered one of the most important human civilizations that still maintains this old style in the era of technology and openness and the multiplicity and diversity of the contemporary building, which made this architecture conservative on its style and old 
structure the focus of the world's attention and interested in the styles of ancient architecture such as the international organization UNICEF.

Considering the civil wars and harsh social conditions that Yemen is going through, this unique type of architecture has been destroyed and destroyed, leading to the disappearance of these works of art. The Yemeni artist and the wall artist had to give aesthetic images inspired by this distinctive architecture by reworking it and highlighting it to others in a contemporary way based on the style of the artist and the nature of the place and the audience in that place to introduce the world to the beauty of this architecture before it was exposed to vanishing in the form of archaeological murals inside Yemeni airports. Architecture here is only a "record of a long cultural period in the history of humanity and art in this building is the result of the bitter conflict between the population, regions or the environment to reach the best adaptation to the environment "(14).

The importance of color in art in general and wall work in particular lies in achieving multiple goals and different ideas where different features of art are highlighted with the intention of seeing the artist come up with his ideas in creating dramatic, dynamic or constant movement in the formation of the general unit of the mural

Style of mural: In this mural Fig. (9) the researcher used blue color in its gradients inspired by the clear sky and the stillness of the sea, to make it a harmonious color for this mural, which was designed from the glass and ceramic mosaics where it was cut into small pieces and touched and the largest variation in the sizes of the pieces as a metaphor for the diversity of the forms of Yemeni buildings in various provinces.

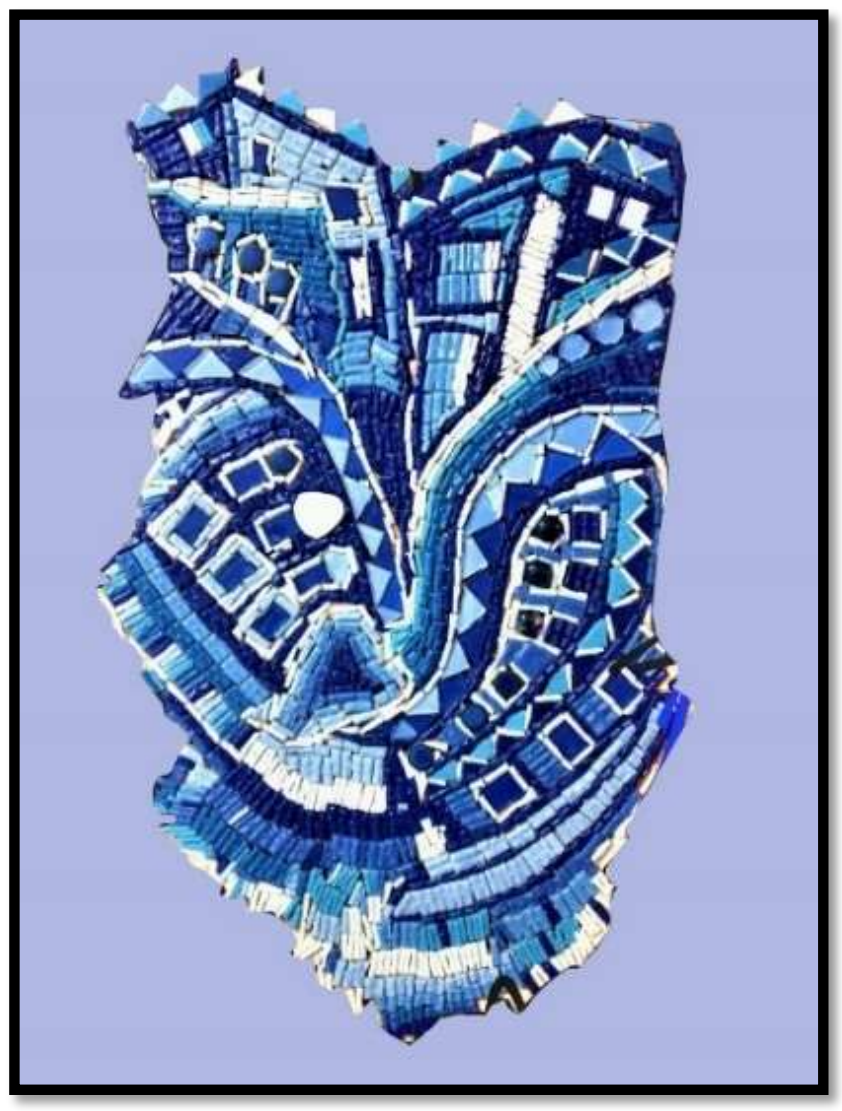

Figure (9) mural of Yemeni architecture

Due to the wars in Yemen in the recent period, the researcher was unable to complete these murals on the ground in Yemeni airports, so she photographed some of the halls of Yemeni airports and accomplished his own vision that appeared clearly in figure (10).. 


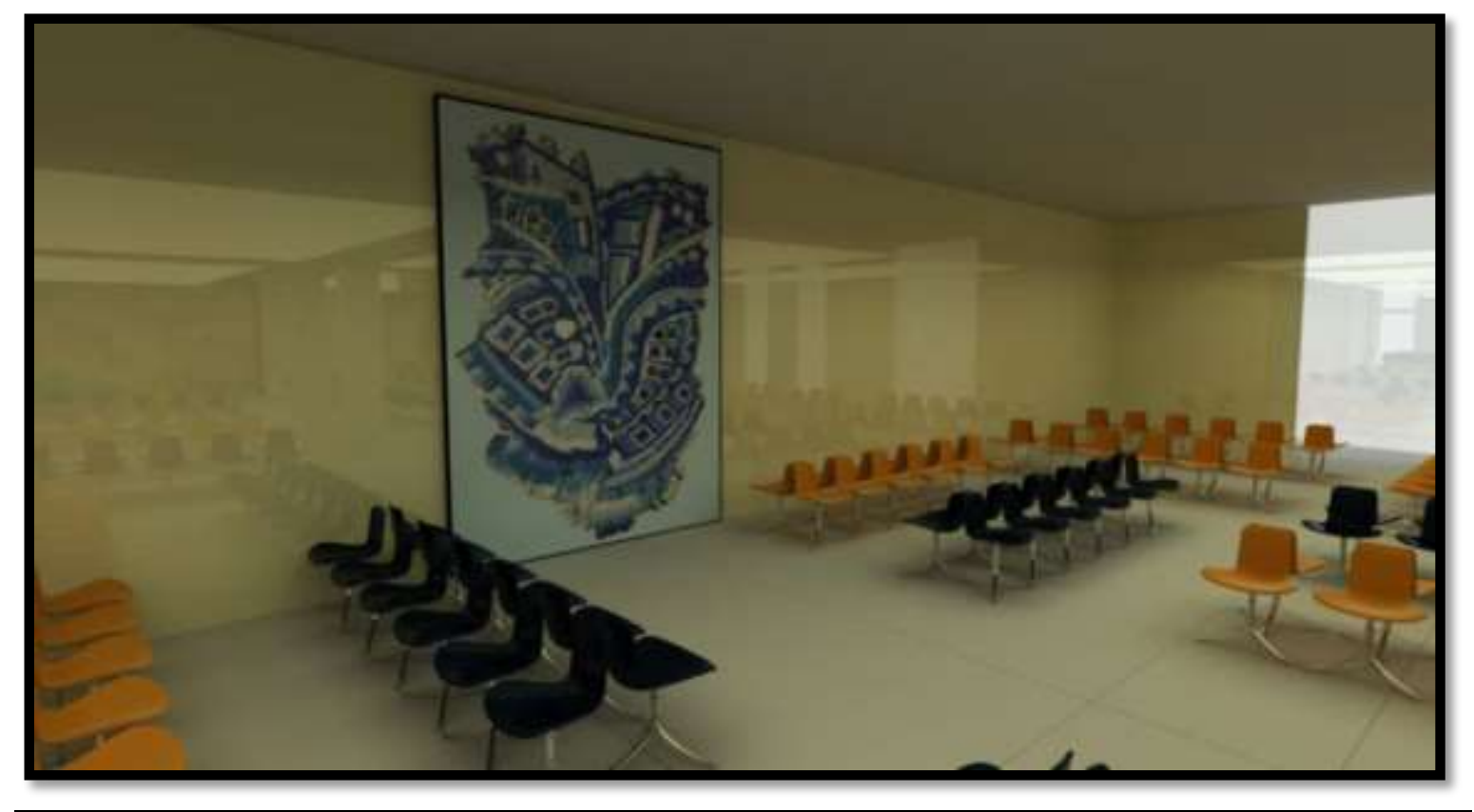

\section{Fig. (10). Imaginary design for one of the lounges of Hodeida Airport in Yemen with the mural of architecture.}

\section{The second axis: Yemeni nature}

The environment is the framework in which man lives and influences him, as it is represented in all the visual scenes or intellectual, ideological, philosophical, religious or natural scenes surrounding the human being.

The relationship between the environment and man has crystallized through theories of psychology where this relationship is a fundamental basis in understanding and interpreting how the environment affects man because the views of the elements of nature are formed and reveal the existence of an elaborate organization in the interior and appearance of nature, where the beauty of these scenes lies in how to organize their parts in harmony and integration to come out in the best form that the researcher was able to photograph in a dialectic..

Nature is a rich source of art and is also a source of various cultural and cultural creations throughout the ages, and the natural environment enjoys diversity, complexity, difference, compatibility, contradiction and continuity, and its virtual compositions are an entity based on the diversity of lines, spaces, shapes and objects, pushing man towards the search for its secrets and stimulating it towards meditation, imagination, imagination and artistic and scientific creativity.

Herbert Reed says, "Nature is the only test for the search for form, and the word nature means the whole organic life and the movement that takes place in the universe, and these are processes that include man as well." (15)

There are many concepts of aesthetic values among philosophers, critics, writers and artists about beauty and its relationship to art and nature. In Aristotle's opinion, he does not copy it, but rather inspires it."(16)

Hence the idea of working on the blood trees of the two brothers on the Yemeni island of Socotra, where the geography of Yemeni nature there is rich in its charm and beauty of its landscapes inspired the artist and invited the recipient to meditate on the beauty of this nature, so it became the first teacher of man from which he derives his artistic elements and how to build them The Socotra archipelago consists of four islands. The Great Island, the Island of the Two Brothers, the Island of Abd al-Kuri and the Island of Pharaoh. The ancient Egyptians described the island of Socotra as the land of the daughter of Punt or the land of paanc, the good land of God" (17)

The ancient Indians described it and said that it is (Dvpa sukharta) meaning the land of bliss and happiness. As for the Greeks, it was mentioned in their records as Dioscorids. Socotra was called by many names, including the island of incense, the island of frankincense, the island of blood of the two brothers, the island of Cain and Abel, in addition to the names of the island derived from Its charm and beauty, such as the island of bliss, the island of blessing and pearls, and the island of the Virgin, as the ancient Romans called it the island of happiness or the blessed island.. 
Style of the mural: The most important characteristic of this island is the growth of some of its trees in strange shapes that give it a kind of beauty through its solid blocks that resemble imaginary human beings to some extent. An imaginary extrapolation of these trees and making them simulate people in different positions, representing the people's objection to the state of the island during the war (Fig.11)

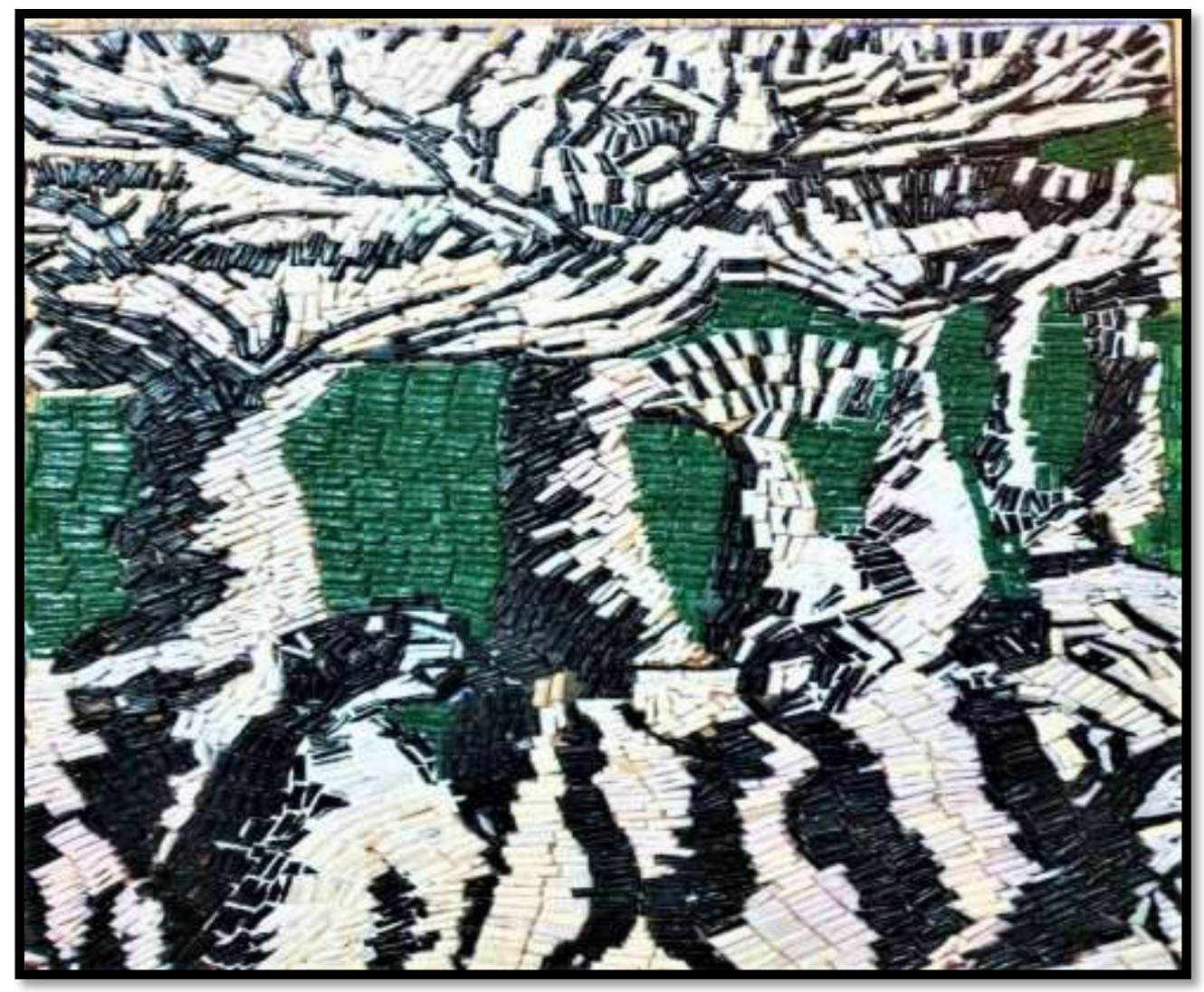

Figure. (11) A mural of the blood trees of the two brothers from the Socotra island with people in different positions.

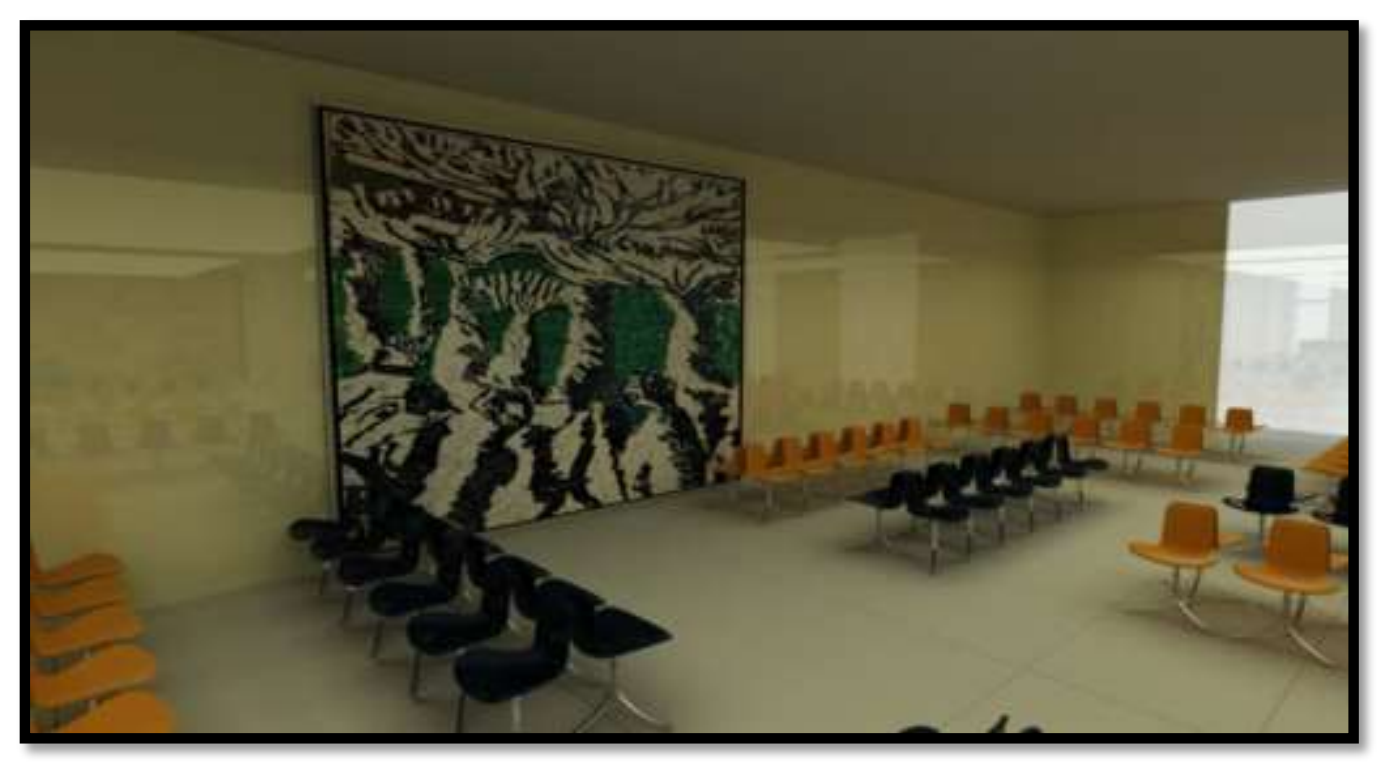

Figure (12). Imaginary design for one of the airport lounges in Hodeida, Yemen, with a mural of nature.

The third axis: the social and psychological status of the Yemeni person

The Yemeni person is going through this period with the scourge of war and health and material problems that made him live in a state of depression so that he no longer sees areas of hope for getting out of these harsh conditions, these many areas may raise the material level and improve the health and psychological condition of 
the Yemeni person. The most important of these areas is the Yemeni natural environment and its richness and features that distinguish it from similar environments such as the growth of coffee and grape trees in most Yemeni regions. The port of the city of Mocha in Yemen is the first port through which the fine Yemeni coffee was exported, which later became one of the finest types of coffee in the world. It was named after Mocha, the proportion of Mocha, which is the region and the port through which Yemeni coffee was previously exported to all countries of the world. The coffee tree was the source of inspiration for the researcher in the third work.

As for the grape tree for which Yemen was famous through ancient historical centuries, it was the second source of murals, where many ancient Yemeni statues and carvings were found containing the fruits and leaves of the distinguished right grape. It was one of the most famous trees available in Yemen and in the green gardens mentioned in the Holy Qur'an, but because of the wars, man neglected If the Yemeni person cared about these two wealth, he would have the possibilities to cultivate and revive them, and the doors of hope and beauty would be opened for him.

For this reason, the idea of the mural inspired by the two trees of coffee and grapes was chosen for two reasons: the first is an attempt to draw the attention of those in charge of the state of this country towards the natural resources in Yemen and to preserve them, because they may be the main artery for restoring life to the right person in light of the disturbances and psychological, health and social problems he faces, and secondly Consolidating its importance in the minds of the Yemeni recipient and the visitor to the Yemeni airport, and giving him an idea of the two best trees that Yemen is famous for since ancient times, in addition to showing the aesthetic value of this mural through the color and its gradations and the lines that depend on its construction. The dawn in the middle of the panel, next to the depiction of the desperate right-hand man due to current events.

Style of the mural: The mural colors with their warm gradations Figure (13) expresses abstract art, showing the turbulent psychological state that the right-hand man suffers from under the current circumstances and civil wars and the resulting social suffering through the expression in the form of a person in the middle of the painting with curved lines used for drawing A group of different patterns, such as: swirls, spiral patterns, and circles devoid of any straight or sharp lines, in order to reach the identification of psychological phenomena and to rely on what is absolutely issued by the human spirit and focus on analytical expressions related to the metaphysical, which gives the mural work dimensions of expressive depth. Through the consistency and clarity of colors, the lines used and the space, the artist tries to give the recipient a sense of the harmony of colors and the balance of their rhythm. 


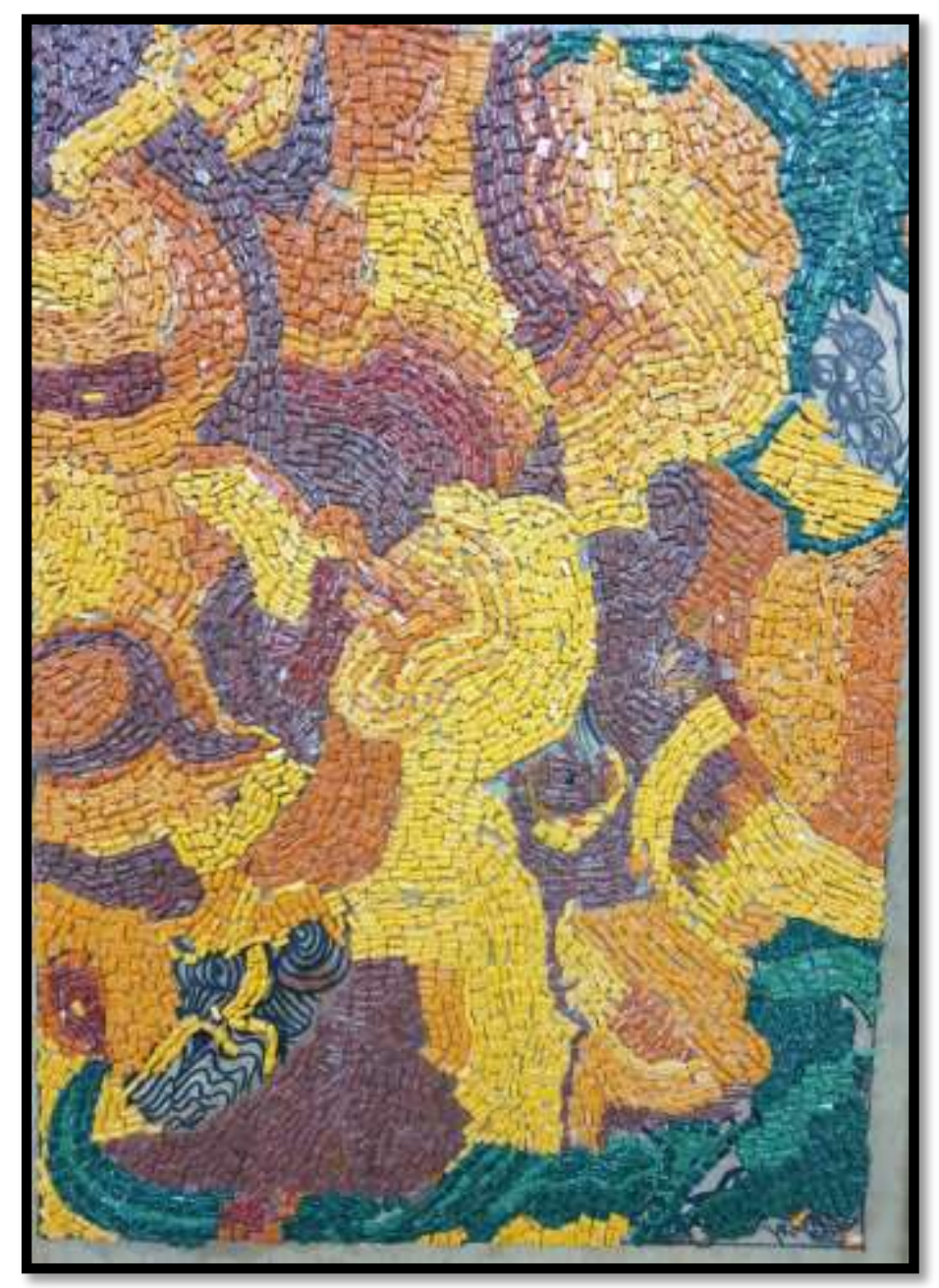

Figure (13) The mural of the social and psychological situation.

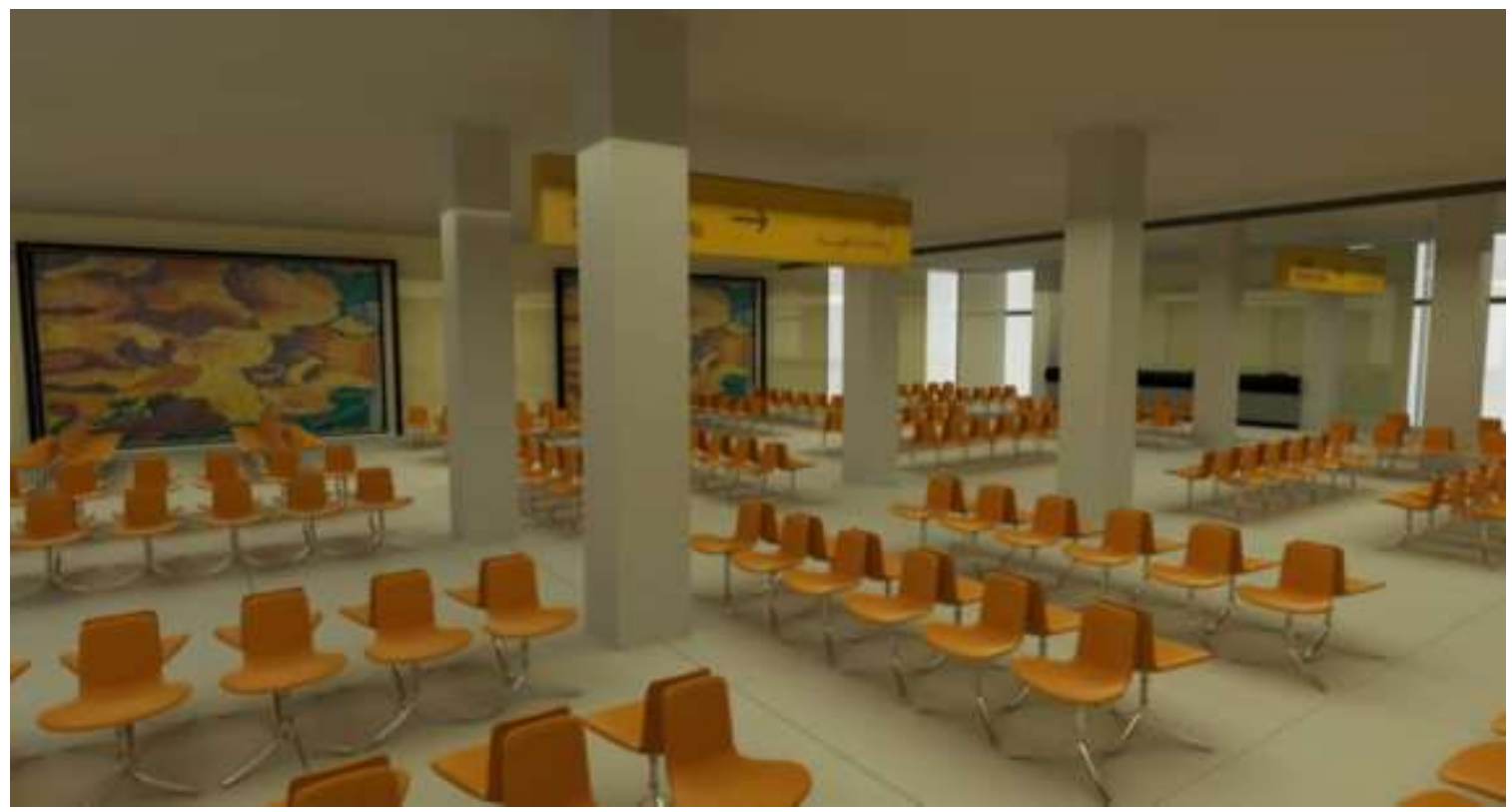

Figure (14) An imaginary design for one of the airport halls of Hodeida in Yemen with mural of the researcher's social and psychological status.

Conclusions 
Many Yemeni institutions' buildings are decorated with murals, paintings, and other subjects related to that region or community. We note that the government of Yemen has taken care of this type of architecture, such as the art of murals, where the murals have helped alleviate the pressures of life and the sources of feelings of joy and knowledge from time immemorial to the present. These places are decorated with strong murals in strong, impressive and imaginative colors in order to attract more people. There are also some frescoes at heritage sites. Most murals are logical and rational. The murals were designed in places where travelers and arrivals are crowded, such as airport lounges, where these murals need to distract the visitors of the place to delay flights, for example, or relieve them of boredom during long waiting periods. These artworks helped them enjoy their boring looking moments .

Due to the wars in Yemen in the recent period, the researcher was unable to complete these murals on the ground in Yemeni airports, so she photographed some of the halls of Yemeni airports and accomplished his own vision that appeared clearly only in its research.

\section{Recommendations}

The mural art works are not suitable for placing in international airport halls except with basic points that are supposed to be taken into account in the mural work to be placed inside airports, where it is recommended to take into account the three main axes: the environment, the design, and the materials in which these murals were completed. That was a general standard for mural painting. On the other hand there are an aesthetic standards for mural painting as a location, shape, height and size of the airports and their relations with the internal and external spaces, as well as the appropriate configuration of the building shape and place and the aesthetic message for the forum through the methods of formulating the elements and shapes and their relationship to each other and the rhythms of colors and their homogeneity or contrast and their relation with lighting factors that gives a sense of diversity and renewal. Finally, the researcher recommends focusing on the topics covered by mural painting, such as topics of a social nature, topics inspired by nature, topics inspired by children's drawings, as well as topics related to heritage. She also urged the importance of topics that depend on the shapes of animals and birds, where the topic is the main element to attract the attention and interest of the recipient.

\section{Acknowledgment}

I would like to thank all of:

ALLAH, by the grace of whom help me to end this project.

Prof. Nermen Elmasry, thank you so much for your diligence in working on this project. You were always the persons who kept me moving forward and I would not have been able to do it without your guidance. It has been a great pleasure working with you and I will never forget all of your kindness.

Prof. Zeinab Mohamed Nour., thank you for providing me with the opportunity to study and learn more about fine arts that I could have ever imagined. Thank you for always being positive, helpful and enthusiastic about fine arts.

Thanks for all my friends.

Thanks for my best family

Signature, Hayat Mohammed Maqbool

\section{References}

1. Stepanskaya AG, Stepansky VV, Sino G. The synthesis of traditional Chinese mural painting and European school of monumental painting in the XXth century and the beginning of the XXIst. Man in India. 2016;96(10):3841-6.

2. Rajput PK. CONTEMPORARY MURALIST OF DELHI. International Journal of Information Movement. (June 2020) .Vol.5 Issue II. Pages (1-12) 
3. Pearman H. Airports: a century of architecture. Laurence King Publishing; 2004. - page 9.

4. Kalakou S, Macário R. An innovative framework for the study and structure of airport business models. Case Studies on Transport Policy. 2013 Jul 1;1(1-2):2-17..

5. Torres P. Case Study: The New Terminal 2E at Paris-Charles De Gaulle Airport. Rapport technique, Airport Systems Planning, Design \& Management, Massachusetts Institute of Technology. 2004 Dec.

6. Ihsan Arsan Al-Rubai, Wael Munir Al-Rashdan, "The Problem of Communication with Heritage in Works of Art", Damascus University Magazine, Volume 19, Issue II, 2003, p. 145.

7- https://www.caixinglobal.com/2017-04-21/101081583.html.

8- https://nostroblogs.wordpress.com/2016/03/13/lart-contemporain-chinois-une-plastique-made-in-toc.

9- Designers and implementers, artist Mohamed Zeinhom and artist Ibrahim Badawy, the mural executed in the front of the airport, it was completed and installed in 1997.

10- JOURNAL OF THE SECTION OF CULTURAL، Studies on the Value of Cultural Heritag ( The role of art in urban gentrifi cation and regeneration: aesthetic, social and economic developments)Luca Palermo University of Macerata 2014 .p 538.

11- https://cosedibergamo.com/2019/04/22/mosaico-di-andrea-mastrovito-aeroporto-di-orio.

12- craftscouncil.org.uk/directory/maker/martin-donlin

13- Martindonlin. com/ projects/indianapolis-airport

14-. Dostall Walter: Notes on traditional engineering in the south of the peninsula, Think and Art Magazine, Issue 35, 1981, p. 62.

15- Ehab Bismarck Al-Saifi: Aesthetic and structural foundations for design, Egyptian writer for printing and publishing 1998, p. 89.

16- Michel Dermieh: Art and Sense, translated by Wajih Al-Baini, Dar Al-Hadathah for Printing and Publishing Beirut, p. 20.

17- Muhammad Abdul Qadir Bamatraf: Hadramout: History of what history neglected, Glimpses of the history of Socotra, Abbad Center for Studies and Publishing The first Edition 2001, p. 139. 